\title{
Sign language instrument for assessing the knowledge of deaf people about Cardiopulmonary Resuscitation*
}

\author{
Nelson Miguel Galindo-Neto ${ }^{1}$ \\ (D) https://orcid.org/0000-0002-7003-165X \\ Magno Batista Lima² \\ (1) https://orcid.org/0000-0003-2220-1172 \\ Lívia Moreira Barros ${ }^{3}$ \\ (1) https://orcid.org/0000-0002-9763-280X \\ Silvana Cavalcanti dos Santos ${ }^{1}$ \\ (1D) https://orcid.org/0000-0002-6649-0423 \\ Joselany Áfio Caetano 4 \\ (1) https://orcid.org/0000-0002-0807-056X
}

Objective: to build and validate the content on Cardiopulmonary Resuscitation (CPR) of a sign language instrument for assessing the knowledge of the deaf. Method: methodological study in which the content validity process was used by 22 specialists in cardiac arrest and 16 deaf people. In the validation of internal consistency, 113 deaf people participated. For the assessment of the deaf, the Assistive Technology Assessment Questionnaire was used and, in the content validity, an instrument with a Likert scale was used, which included the content, clarity, objectivity, organization and language. Items with a minimum agreement of $80 \%$ were considered valid, according to the Content Validity Index (CVI) and binomial test. The internal consistency was verified by Cronbach's alpha. Results: The instrument contains 11 questions about the identification of cardiorespiratory arrest, activation by aid and high quality chest compression. It had a minimum content validity of $81 \%$ by the specialists, $90 \%$ by the deaf participants and internal consistency by the Cronbach alpha of 0.86 , being considered high. Conclusion: the instrument can be used in research to survey the previous knowledge of deaf people about CPR, as well as in pre and/or post-testing studies that test educational interventions with this public.

Descriptors: Persons with Hearing Impairments; Sign Language; Cardiopulmonary Resuscitation; Knowledge; Validation Studies; Health Education.

\section{How to cite this article}

Galindo-Neto NM, Lima MB, Barros LM, Santos SC, Caetano JA. Sign language instrument for assessing the knowledge of deaf people about Cardiopulmonary Resuscitation. Rev. Latino-Am. Enfermagem. 2020;28:e3283. [Access $\underset{\text { month day }}{\uparrow} \underset{\text { year }}{1}]$; Available in: DOI: http://dx.doi.org/10.1590/1518-8345.3535.3283. 


\section{Introduction}

The deaf constitute a category of the world's population of some 466 million people, estimated by the World Health Organization to reach 900 million by $2050^{(1)}$. Communication of the deaf, when hearing impairment is greater than $40 \mathrm{~dB}$, occurs by means of a gesture stimulus(2), Thus, this public has difficulty in accessing information on various health-related topics(3).

The communication barrier makes it impossible to empower deaf people about life-threatening health situations for which they could know how to act and contribute to reducing mortality. An addiction incompatible with life and in which the intervention of people who are not health professionals is associated with greater survival is out-of-hospital cardiac arrest $(C R A)^{(4)}$. It affects almost 300,000 people a year in the United States ${ }^{(5)}$ and 100,000 in Brazil(6).

To assist victims of CRA, all individuals with cognitive conditions to perform their identification and motor skills to perform chest compressions should be taught on this subject(4). One of these audiences is composed of the deaf, who may be present in various social environments and witness a CRA outside the hospital, so that the need for investment in research that takes into account the specificities of teaching cardiopulmonary resuscitation (CPR) to this part of the population is highlighted.

In order to make scientific research on the teaching of CPR for the deaf possible, it is pertinent to evaluate the knowledge before and after educational interventions. In order to deal with internal validity, such studies should carry out measurements of the knowledge of the deaf about CPR from instruments built and validated.

Nursing is the professional category that has health education present in its professional exercise ${ }^{(7)}$. Therefore, as it has expertise in emergency related issues, it constitutes a strategic professional category for health education for deaf people on CPR. Thus, it is important to note that research that includes tools to assess knowledge of deaf people about CPR is important for such a category, which may use such tools in studies that test various interventions and teaching strategies in teaching CPR to deaf people. In addition, this tool could be used in institutions teaching deaf people even in the absence of the professional nurse.

Thus, the study aimed to build and validate the content on Cardiopulmonary Resuscitation of a sign language instrument for the assessment of the knowledge of deaf people.

\section{Method}

Methodological research, operated according to psychometry, from the theoretical, empirical and analytical poles ${ }^{(8-9)}$. The theoretical pole corresponded to the first stage: the construction of the instrument. The empirical pole consisted of the second stage, of content validity by 22 professionals, the third stage, of validation by 16 deaf people, and the fourth stage, of application with 113 other deaf people to verify internal consistency. In the analytical stage, content validity and reliability were calculated/verified.

The study was carried out in three educational institutions located in Fortaleza - CE. The first two were state public schools: one dedicated exclusively to the education of the deaf and the second dedicated to the teaching of the deaf and hearing. The third institution was philanthropic, religious and aimed at teaching and social inclusion of the deaf.

In the first stage, construction of the instrument, questions were elaborated based on the recommendations for lay people from the Brazilian Society of Cardiology, American Health Association, Resuscitation Councils of Asia and Europe regarding the way to identify the CRA, the need to call for help and the correct chest compression ${ }^{(10-13)}$. The distribution of the themes for each question is summarized in Figure 1.

\begin{tabular}{|c|c|}
\hline Block of questions & Theme of each question \\
\hline \multirow[t]{2}{*}{ Identify } & $\begin{array}{l}1 \text { - Correctly identify cardiorespiratory arrest } \\
\text { with verification of the victim's responsiveness } \\
\text { and breathing. }\end{array}$ \\
\hline & $\begin{array}{l}2 \text { - Emergence and severity of cardiorespiratory } \\
\text { arrest. }\end{array}$ \\
\hline \multirow{2}{*}{ Call for help } & $\begin{array}{l}3 \text { - Calling for help before starting chest } \\
\text { compressions. }\end{array}$ \\
\hline & $\begin{array}{l}4 \text { - Telephone contact number with the Mobile } \\
\text { Emergency Care Service (MECS). }\end{array}$ \\
\hline \multirow{7}{*}{ Chest compression } & $\begin{array}{l}5 \text { - Correct moment when chest compression } \\
\text { should be performed. }\end{array}$ \\
\hline & $\begin{array}{l}6 \text { - Position the victim correctly in a rigid and } \\
\text { level place. }\end{array}$ \\
\hline & $\begin{array}{l}7 \text { - Place hands in the center of the victim's } \\
\text { chest for compression. }\end{array}$ \\
\hline & $\begin{array}{l}8 \text { - Position shoulders at } 90^{\circ} \text { with the victim's } \\
\text { chest. }\end{array}$ \\
\hline & $\begin{array}{l}9 \text { - Perform chest compression with as much } \\
\text { force as possible. }\end{array}$ \\
\hline & $\begin{array}{l}10 \text { - Relay the rescuer who compresses every } \\
\text { two minutes. }\end{array}$ \\
\hline & $\begin{array}{l}11 \text { - Do not stop compressions until the victim } \\
\text { wakes up or until health professionals arrive. }\end{array}$ \\
\hline
\end{tabular}

Figure 1 - Themes of the instrument questions to assess the knowledge of the deaf about Cardiopulmonary Resuscitation. Fortaleza, CE, Brazil, 2018

To expand the possibility of understanding the instrument, the questions were built by a team composed 
of a nurse with experience in urgency and emergency and in the teaching of CRA, by a Libras interpreter and by a teacher from a deaf education institution fluent in Libras. Both, in a face-to-face meeting, formulated the instrument's 11 questions, as well as the five alternatives for each one.

Each question was composed of five answer options (multiple choice), with only one correct alternative, a clear and concise statement, which requested the correct alternative related to the competence/ information evaluated. The alternatives that were not correct were built from possible situations so that the correctness would not occur by the logical selection of the alternatives, except the last alternative for each question (the letter " $\mathrm{e}$ "), which was standardized with the option "I don't know", which could be marked by the deaf.

In two questions (referring to the location of the rescuer's position and hands for chest compression), the alternatives had images to facilitate their understanding. In the alternatives of all questions, the letters $a, b, c, d$ and e were accompanied by images of hands with that letter of the alphabet in Libras. It should be noted that all images of the instrument were built by a professional designer, hired exclusively for this purpose, using the Corel Draw program.

In the second stage, content validation, the instrument was submitted to content validation by experts in CRA. The definition of the sample for this step occurred from the formula for the finite population $n=Z a^{2} \cdot P(1-P) / e^{2(14)}$. The confidence level (Za) used was $95 \%$; the proportion of expert agreement ( $P$ ) used was $85 \%$ and the acceptable difference (e) used was $15 \%$. Using these parameters, we obtained the sample quantity of 22 .

Professionals with expertise in CRA were recruited from the websites of the public institutions of higher education in Fortaleza - CE where the collection of e-mail addresses of teachers in the emergency and intensive care areas of the undergraduate courses in Nursing took place. Through e-mail contact with such professionals, there was a request for nominations of other professionals (snowball strategy) so that indications of names of professionals from the states of Rio de Janeiro, São Paulo, Minas Gerais, Paraíba and Pernambuco were obtained.

The criteria for the selection of specialists dealt with academic, scientific and professional aspects(15): were used as inclusion criteria to be a bachelor in Nursing and to have teaching, assistance or CRA research experience. The exclusion criterion was the non-fulfillment of the data collection instrument. Thus, 54 professionals were contacted by e-mail to whom the Term of Free and Informed Consent (FICT), the instrument in the validation process and the instrument for data collection were sent. Thus, the 11 questions of the instrument in process of validation were analyzed by the professionals, who filled in the data collection instrument regarding its evaluation/ validation, composed of 14 questions for the characterization of the specialists and eight questions, on a Likert type scale, for the professional to record his level of agreement about the scope, relevance and clarity of the content, objectivity, organization and language.

For the registration of the experts' agreement, the instrument had the options 1 = I totally disagree, $2=$ I neither agree nor disagree, 3 = I partially agree and $4=$ I totally agree. In addition, for each question evaluated, space was made available for the registration of opinions/suggestions.

The 22 professionals who first sent the response were included in the sample of this phase of the survey. After analyzing the suggestions obtained, the recommendation of reformulating three sentences was followed to make the alternatives more understandable.

As it was an instrument aimed at the deaf, the questions were recorded in studio in the Brazilian Sign Language (Libras) by a duly certified professional (holder of a diploma of technical course in interpreting Libras), who worked as an interpreter in one of the institutions for teaching deaf people. Thus, the evaluation instrument was composed of two parts: the first in written/printed Portuguese and the second in Libras, in video format. Both to be used concomitantly in the evaluation of deaf people's knowledge about CPR: the video for the questions and alternatives in Libras to be watched and the printed part for recording the answers.

In the third stage, validation by the deaf, both parts of the instrument (printed and video) were evaluated by 16 participants in a professional course in a philanthropic institution. This institution, with about 150 deaf students enrolled, had a teaching offer from the first to the ninth year, in addition to offering a professional course in administrative assistant. The sample quantity of this stage was defined for convenience: through prior contact with the coordination of the institution, it recommended the evaluation of the instruments by the students of the vocational course in view of the availability of such class.

The inclusion criterion for the participants of this stage was to have a link as a student of the institution and the exclusion criterion was to have 
cognitive impairment that made it impossible to judge the material. This commitment was verified by consulting the medical reports, existing in the school office, which were a requirement for the registration of students. These reports included medical records regarding deafness, presence of comorbidities and cognitive impairment.

The communication process with deaf students was carried out by the presence of a Libras interpreter, from the said educational institution, who asked the participants to sign the FICT. The participants were accommodated in the classroom and seated in school desks in a semicircle. For each one, the printed version of the instrument was delivered and the video was projected to the center of the semicircle in a date show. Each question was projected on video and, after exposing the statement and the five alternatives in the video, the students were invited by the interpreter to read the same question in the printed part of the instrument. Thus, there was video exposure and reading of the 11 questions of the instrument.

After the presentation of all questions, to record the evaluation of deaf students, the participants were given the Assistive Technology Assessment Questionnaire (ATAQ). This questionnaire, constructed and validated for people with disabilities to assess their understanding of assistive technologies, has 14 questions about the objective, clarity, relevance and interactivity for which it is possible for the participant to mark, on the response scale, the "inappropriate", "partially appropriate" or "appropriate" options for each item assessed(16). For the use of ATAQ, each question was read by the researcher, with concomitant translation into Libras by the interpreter. This reading/ translation took place in one question at a time and after each question was read, the deaf were asked to fill out the answer.

In the fourth step, to check the internal consistency, the instrument was applied to the deaf. For this, there was the scheduling with the coordination of the three educational institutions that had deaf students in Fortaleza - CE. The classes of the three shifts were approached in their class schedule with the authorization of the teacher of the referred schedule.

The inclusion criterion was to be duly enrolled in the educational institution and the exclusion criteria were: not having attended classes at the educational institution, so that the participant was not present on the day scheduled for data collection, and being affected by cognitive impairment that made participation in the research impossible. This commitment was verified by consulting the existing medical reports in the secretariats of educational institutions.

Of the 360 deaf students enrolled in the three institutions, 247 were excluded because they were not present on the day scheduled for data collection. Thus, 113 integrated the sample of this stage. It should be noted that this quantitative is compatible with the sample to determine internal consistency, which should be from five to ten participants per item ${ }^{(17)}$. Thus, considering that the instrument has 11 items, the sample to estimate its internal consistency would be from 55 to 220 participants.

The application of the instrument was mediated by a Libras interpreter. The FICT was requested to be signed and, with the participants accommodated in their respective school desks, the printed instrument was delivered. The video part of the instrument was projected on the whiteboard located in front of the room. Each question was contemplated, in turn, so that the projection of the question/answer and five alternatives took place, with subsequent provision of time for the recording of the answer in the printed part of the instrument.

In the analytic pole, the data were analyzed in the $\mathrm{R}$ software, version 3.1.1. In the content validation with the professionals, the Content Validity Index (CVI) was used, which was calculated, for each item, from the amount of experts who agreed with the item, sum of the answers $3=$ partially agree and $4=$ fully agree, divided by the total amount of experts. In content validation with deaf people, since the questionnaire used, ATAQ, had the response options inadequate, partially adequate and adequate, the CVI was calculated, per item, from the quantity of deaf people who considered the adequate item divided by the total number of deaf people who validated the material.

For the analysis about the proportion of agreement having been equal or superior to $80 \%$, value determined to consider the valid item ${ }^{(18)}$, the binomial test was used. The reliability of the instrument was verified through internal consistency from the Cronbach alpha calculation. For Cronbach's alpha classification, which varies from 0 to 1 , it was considered very low for values below 0.30 ; low for values between 0.3 and 0.6 ; moderate for values above 0.6 and below 0.75 ; high for values between 0.75 and 0.9 and very high for values above $0.9^{(17)}$.

The research was conducted in accordance with Resolution 466/12 and obtained approval from the Research Ethics Committee of the Federal University of Ceará according to opinion 2,108,475. 


\section{Results}

The instrument had 11 questions that included the identification of CRA, the triggering of aid and the performance of CPR. In addition, it was composed of two parts: the first in video, with the questions and alternatives in Libras and the second printed, with the

written content for recording the answer. In the video part, in a standard way, the interpreter presented herself with a black blouse during the narration of all the questions and with a green blouse in the narratives of the answer alternatives. Figure 2 shows how the same question was addressed in the video (Libras) and printed parts.

\section{Question in the video (Brazilian sign langu}

Written/printed question of the instrument

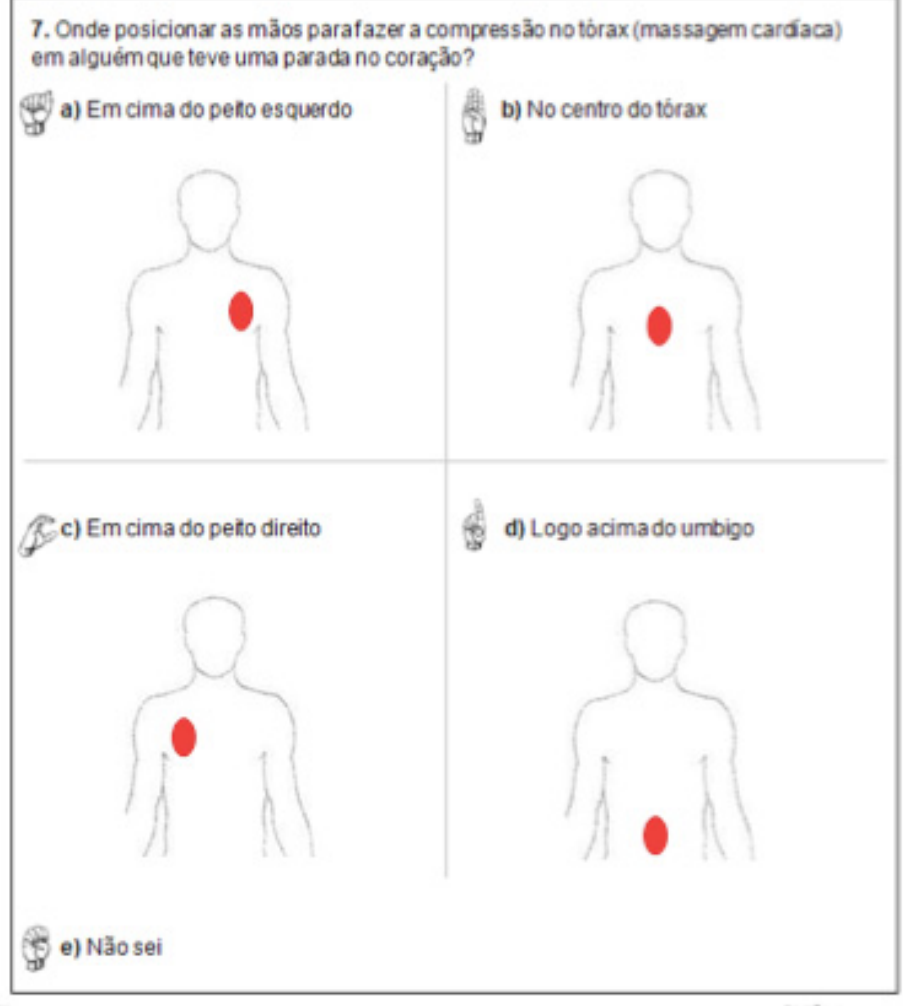

7. Onde posicionar as mãos parafazer a compressão no tórax (massagem cardiaca) em alguêm que teve uma parada no coração?

$$
\text { (8) }
$$
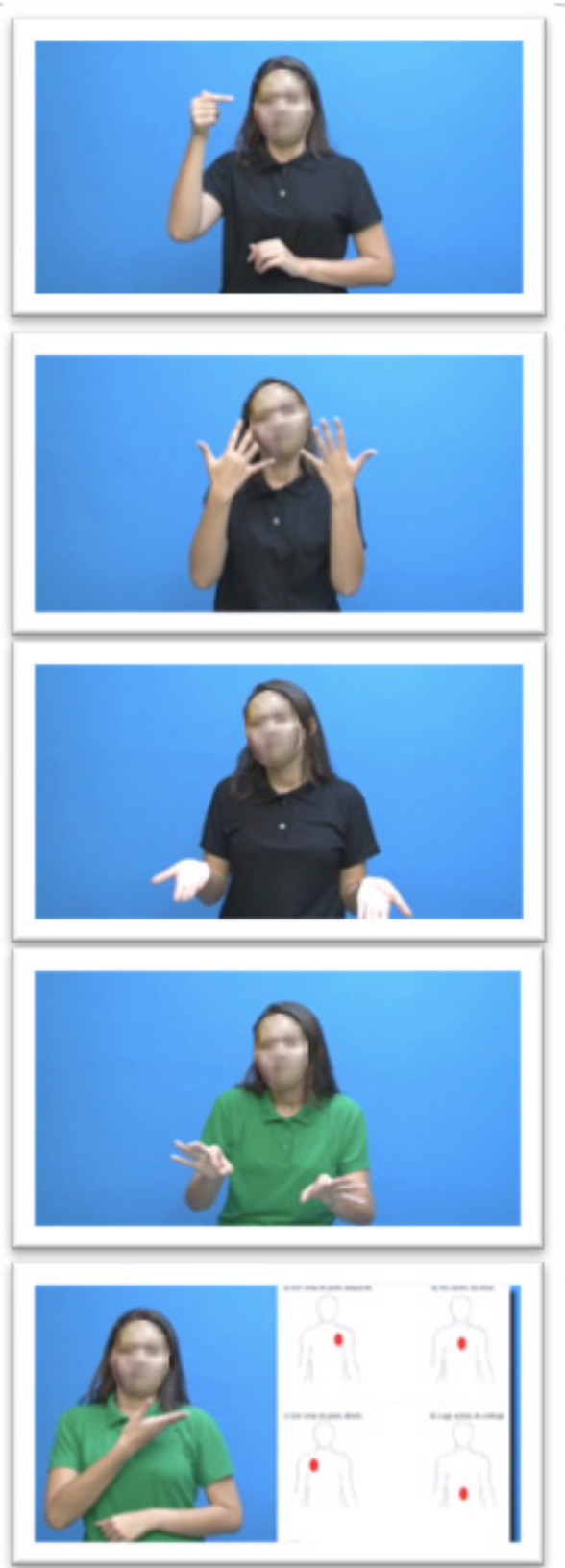

Figure 2 - Question of the instrument to evaluate the knowledge of deaf people on Cardiopulmonary Resuscitation. Fortaleza, CE, Brazil, 2018

The video version of the instrument was finished with a duration of ten minutes and 50 seconds, while the printed/written version was composed of five pages. The pages of the printed part of the instrument and the questions and alternatives that compose it can be seen in Figure 3. 


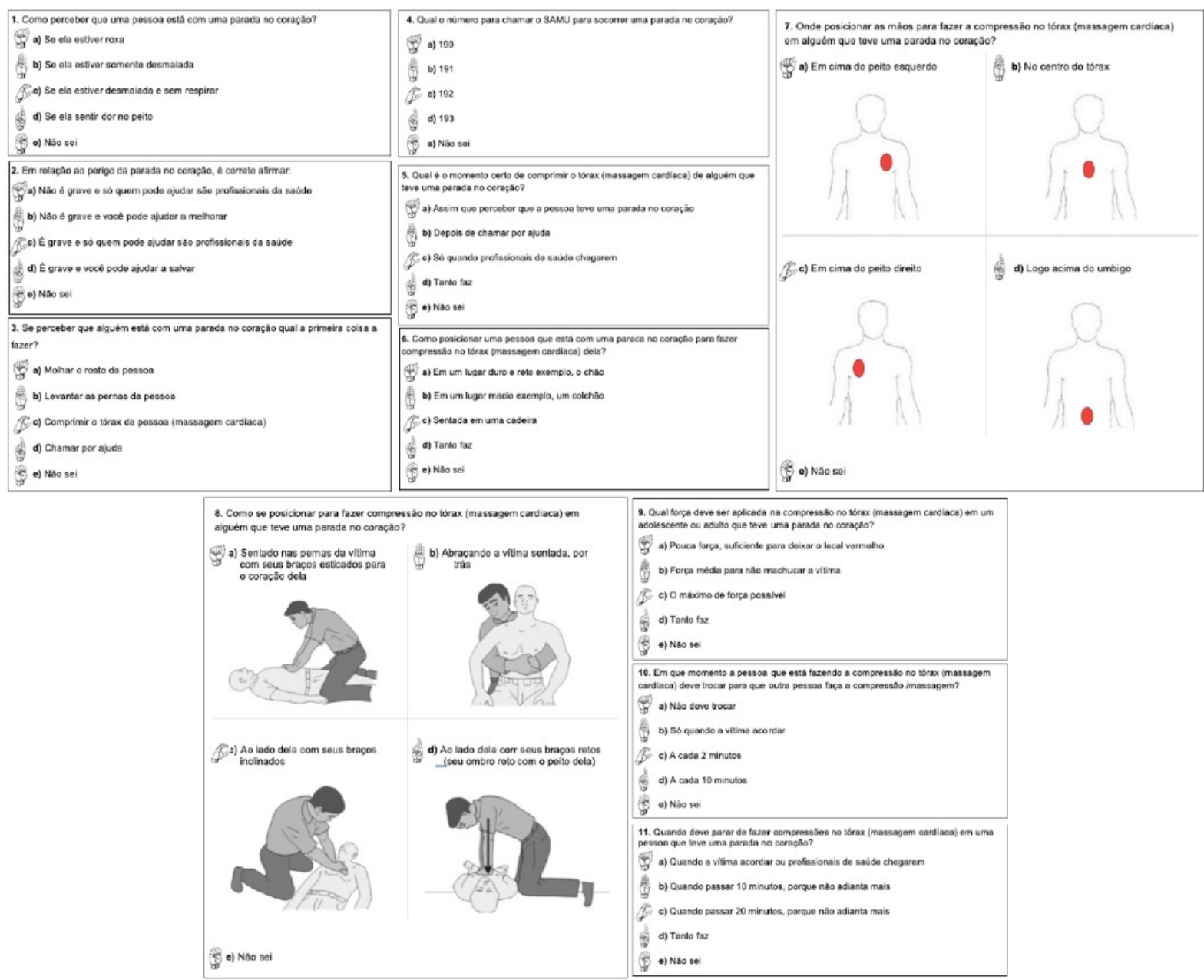

Figure 3 - Pages of the instrument to evaluate the knowledge of the deaf on Cardiopulmonary Resuscitation. Fortaleza, CE, Brazil, 2018

The specialists who participated in the validity of the contents of the instrument were all nurses, being nine $(40.9 \%)$ doctors, eight $(36.4 \%)$ masters and five $(22.7 \%)$ specialists. The 22 professionals had assistance experience in the areas of Emergency and Emergency or Intensive Care and had participated in training courses on CPR. In addition, 19 (86.3\%) were teachers of higher education or specialization courses and taught curricular components related to CRA.

The content validation pointed out agreement higher than $80 \%$ in all questions and, due to the nonsignificance of the binomial test, all questions showed agreement statistically higher than 0.8. Thus, all questions were considered valid in terms of content by the experts (Table 1 ).

Table 1 - Experts agreement about the instrument to assess the knowledge of deaf people on Cardiopulmonary Resuscitation. Fortaleza, CE, Brazil, 2018

\begin{tabular}{|c|c|c|c|c|c|c|c|c|c|c|}
\hline \multirow{2}{*}{ Question } & \multicolumn{2}{|c|}{ Content } & \multicolumn{2}{|c|}{ Clarity } & \multicolumn{2}{|c|}{ Objectivity } & \multicolumn{2}{|c|}{ Organization } & \multicolumn{2}{|c|}{ Language } \\
\hline & $\mathrm{CVI}^{*}$ & $\mathbf{p}^{\dagger}$ & CVI & p & CVI & p & CVI & p & CVI & p \\
\hline 1 & 0.81 & 0.424 & 0.81 & 0.42 & 0.95 & 0.972 & 0.86 & 0.661 & 0.90 & 0.863 \\
\hline 2 & 1 & 1 & 0.86 & 0.66 & 0.95 & 0.972 & 0.86 & 0.661 & 0.95 & 0.972 \\
\hline 3 & 0.95 & 0.972 & 1 & 1 & 1 & 1 & 0.90 & 0.863 & 0.95 & 0.972 \\
\hline 4 & 1 & 1 & 1 & 1 & 1 & 1 & 1 & 1 & 1 & 1 \\
\hline 5 & 0.95 & 0.972 & 0.86 & 0.66 & 0.95 & 0.972 & 0.86 & 0.661 & 0.95 & 0.972 \\
\hline 6 & 1 & 1 & 1 & 1 & 1 & 1 & 0.95 & 0.972 & 0.95 & 0.972 \\
\hline 7 & 1 & 1 & 1 & 1 & 1 & 1 & 1 & 1 & 0.95 & 0.972 \\
\hline 8 & 1 & 1 & 1 & 1 & 1 & 1 & 0.95 & 0.972 & 0.90 & 0.863 \\
\hline 9 & 0.86 & 0.661 & 0.81 & 0.42 & 0.86 & 0.661 & 0.86 & 0.661 & 0.95 & 0.972 \\
\hline 10 & 0.95 & 0.972 & 0.95 & 0.97 & 1 & 1 & 1 & 1 & 0.90 & 0.863 \\
\hline 11 & 1 & 1 & 1 & 1 & 1 & 1 & 1 & 1 & 1 & 1 \\
\hline
\end{tabular}

${ }^{*} \mathrm{CVI}=$ Content Validity Index $;{ }^{\dagger} p=$ Binomial test 
Regarding the deaf who evaluated the instrument, $13(81.2 \%)$ were female; ten $(62.5 \%)$ were married and nine $(56.2 \%)$ had no children. According to the assessment of the deaf, the questions of the instrument (statements and alternatives) were considered understandable by all. There was unanimous agreement (with binomial test $=1$ ) on questions about the suitability of using the material, ease and encouragement for use, encouragement for learning, attractiveness, clarity and encouragement for reflection. The only item in which there was no total agreement was about the material enabling interaction, which obtained 95\% agreement for the deaf and whose binomial test was 0.972 . It is noteworthy that the deaf did not present any suggestion of adjustment / improvement for the instrument.

The instrument's reliability was attested by the high internal consistency observed from Cronbach's alpha equal to 0.82 .

\section{Discussion}

The constructs addressed by the instrument questions included three stages of assistance: the identification of CRA, the correct activation by help and the performance of CPR. This finding corroborates a study carried out in Spain, which built and validated a tool for the evaluation of the quality of CPR and obtained, from specialist professionals, the recommendation on the relevance of evaluating the identification of CRA, the activation by help and the performance of $\mathrm{CPR}^{(19)}$. Such findings converge with a Brazilian study, which dealt with the construction and validation of educational technology for deaf people about CPR, in which the same steps of assistance were addressed(20). Thus, the relevance of these three constructs to be addressed in the instrument's questions is highlighted.

The identification of the CRA and the call for help are ratified by the fact that the assistance of health professionals depends on someone to identify the problem and inform the health team of the situation ${ }^{(11,21)}$. While the high quality of CPR, composed of the correct positioning of the victim and the rescuer, the position of the hands in the center of the chest, the correct speed and depth, the minimization of interruptions and the return of the chest between compressions, impacts the maintenance of perfusion blood flow and the return of spontaneous circulation, as pointed out by an American multicenter study ${ }^{(21)}$.

The process of selecting the themes of the questions corroborated the positive evaluation of the experts, as there was agreement that the content was correct and sufficient to assess the necessary dimensions of the theme. Such agreement converges with that found in a study from Venezuela, which contemplated the construction and validation of educational technology about oral health(22). The findings mentioned above confirm the need for evaluation / validation of instruments by specialists before being used in research.

The construction of the instrument aimed at the deaf demanded attention to the communication specificities of this population. About this, results of research carried out in South Africa showed that the deaf point to the use of sign language and images as factors that facilitate their understanding(2). This finding confirms the recommendations of professionals working in the education of the deaf about the need for communication to occur from visual stimuli (images) and sign language and, when writing is necessary, occur with simple concepts and short texts ${ }^{(23)}$. The caution with writing is due to the linguistic barrier of the deaf with writing, which causes difficulty in understanding(24).

In this way, the instrument is supported by having the letters of the alternative answers $(a, b, c, d$ and e) accompanied by an image of that letter in Libras, consisting of two parts (one on video/Libras, for effective communication and the other written/printed to record responses) and have your text prepared with the help of an interpreter and deaf teacher.

The fulfillment of the specifics of communication with the deaf reflected in the experts' agreement about the clarity, objectivity, organization and language of the instrument. Such agreement is similar to that found in a study that evaluated video aimed at teaching the human genome conducted in New York ${ }^{(25)}$. In this context, it is noteworthy that the process of communication between professionals and the population, in instruments, requires caution, organization and adaptation of technical terms so that the data from their use are not biased and, therefore, do not compromise quality and feasibility of use.

The assessment of the instrument by deaf people was relevant in view of the possibility of obtaining suggestions regarding the reformulation of confusing or poorly understood text, images or text.

The difficulty in understanding the population, regarding health content, is verified in two studies: the first, carried out in the United States, pointed out that $80 \%$ of the virtual page content was not understood by patients ${ }^{(26)}$. The second, from Germany, showed that the target population (patients) did not understand the content of educational materials related to ophthalmology, which were distributed/ used in 32 hospitals ${ }^{(27)}$.

The aforementioned results diverge from Brazilian research on instrument validation for assessing the knowledge of adolescents about leprosy, whose results 
showed that the target audience considered the instrument understandable ${ }^{(28)}$.

Given the dichotomy of the results of the studies, the relevance of, in the process of validating the content of instruments, highlighting the opinion of the target audience for whom the instrument is intended is highlighted. The importance of popular participation in the evaluation of instruments is pointed out in a study carried out in Puerto Rico, which involved members of the school community in the validation of an instrument on school violence. The results of this study showed that the participation of the target audience provided important information for researchers and empowered the community to recognize their role in solving the problem ${ }^{(29)}$.

The deaf considered the instrument to be easy to use and attractive. This finding converges with that found in a study in which technology for teaching sign language was conducted in Bogotá(30). Thus, it points out the need for instruments aimed at the deaf to be attractive and easy to use in order to make the information collection process carried out through its use feasible.

The study's limitation refers to the fact that it was carried out in educational institutions for the deaf so that the findings may differ from research carried out with deaf people not included in the school context.

The construction and validation of the sign language instrument for assessing the knowledge of the deaf about Cardiopulmonary Resuscitation contributes to the advancement of scientific knowledge due to the availability of an instrument whose construction was carried out in a multidisciplinary way (by a nurse, Libras interpreter and teacher of deaf), based on research steps, from which it was possible to verify its content validity, internal consistency and understanding of the target audience. Thus, the instrument can be used in teaching, research and extension about the knowledge of deaf people about CPR.

Nursing acts in health education, in the care of the deaf population, in research on the knowledge of the population and in health services in which CRA occurs. Therefore, this professional category is in a strategic position to use the instrument on the knowledge of deaf people about CPR. In addition, this study presents a method that can be replicated in nursing research that contemplates the construction and validation of instruments for assessing the knowledge of deaf people about other health topics.

\section{Conclusion}

There was the construction of the instrument in sign language to assess the knowledge of deaf people about Cardiopulmonary Resuscitation. It was composed of two parts: the first in video/Libras to establish better communication and the second written/printed to record responses. Both parties had the same questions, which included the stages of identification of the CRA, activation by help and high-quality chest compressions.

The sign language instrument for assessing the knowledge of deaf people about Cardiopulmonary Resuscitation had content validity by specialists and deaf participants and high internal consistency by Cronbach's alpha. This instrument can be used in research to survey the deaf's prior knowledge about CPR, as well as in pre and / or post-test studies that test educational interventions with this audience.

\section{References}

1. World Health Organization. Deafness and hearing loss. [Internet]. Geneva: World Health Organization; 2018 [cited 2019 Feb 20]. Available from: http://www.who.int/ news-room/fact-sheets/detail/deafness-and-hearing-loss 2. Chininthorn $P$, Glaser M, Tucker WD, Diehl JC. Exploration of deaf people's health information sources and techniques for information delivery in Cape Town: a qualitative study for the design and development of a mobile health app. JMIR Hum Factors. [Internet]. 2016 [Cited 2019 Feb 20];3(2):e28. Available from: https:// www.ncbi.nlm.nih.gov/pubmed/27836819

3. Santos AS, Portes AJF. Perceptions of deaf subjects about communication in Primary Health Care. Rev. Latino-Am. Enfermagem. [Internet]. 2019 [cited 2019 Feb 20];27:e3127. Available from: http://www.scielo. br/pdf/rlae/v27/0104-1169-rlae-27-e3127.pdf

4. Panchal AR, Berg KM, Cabañas JG, Kurz MC, Link MS, Rios MD, et al. 2019 American Heart Association focused update on systems of care: dispatcher-assisted cardiopulmonary resuscitation and cardiac arrest centers: an update to the American Heart Association Guidelines for Cardiopulmonary Resuscitation and Emergency Cardiovascular Care. Circulation. [Internet]. 2019 [cited 2019 Nov 23];140:e1-e9. Available from: https://www.ahajournals.org/doi/pdf/10.1161/ CIR.0000000000000733

5. Mathias J. Holmberg MJ, Ross CE, Fitzmaurice GM, Chan PS, Duval-Arnould J, et al. Annual incidence of adult and pediatric in-hospital cardiac arrest in the United States. Circ Cardiovasc Qual Outcomes [Internet]. 2019 [cited 2019 Feb 20];12:e005580. Available from: https://www.ahajournals.org/doi/pdf/10.1161/ CIRCOUTCOMES.119.005580

6. Bernoche C, Timerman S, Polastri TF, Giannetti NS, Siqueira AWS, Piscopo A, et al. Atualização da 
diretriz de ressuscitação cardiopulmonar e cuidados cardiovasculares de emergência da Sociedade Brasileira de Cardiologia - 2019. Arq Bras Cardiol. [Internet]. 2019 [Acesso 23 nov 2019];113(3):449-663. Disponível em: http://publicacoes.cardiol.br/portal/abc/ portugues/2019/v11303/pdf/11303025.pdf

7. Whitehead D. Exploring health promotion and health education in nursing. Nurs Stand [Internet]. 2018 [cited 2019 Feb 20];33(8):38-44. Available from: https:// search.proquest.com/openview/95d8f91c2e5e08cca34 bbcbece8a21cc $/ 1$ ?pq-origsite $=$ gscholar $\&$ cbl $=2042228$.

8. Pasquali L. Psychometrics. Rev Esc Enferm USP. [Internet]. 2009 [cited 2019 Nov 25];43(Sp.):992-9. Available from: http://www.scielo.br/pdf/reeusp/ v43nspe/a02v43ns.pdf

9. Rosana KSM, Marcos AFJ, Diana PSRP, Allyne FV, Viviane EPS, Elizabeth B. Pasquali's model of content validation in the nursing researches. Rev Enferm. [Internet]. 2015 [cited 2019 Nov 25];5(4):127-35. Available from: http://www.scielo.mec.pt/pdf/ref/ vserIVn4/serIVn4a14.pdf

10. Kleinman ME, Goldberger, ZD, Rea T, Swor RA, Bobrow BJ, Brennen EE, et al. 2017 American Heart Association focused update on adult basic life support and cardiopulmonary resuscitation quality: an update to the American Heart Association Guidelines for Cardiopulmonary Resuscitation and Emergency Cardiovascular Care. Circulation. [Internet]. 2018 [cited 2019 Feb 20];137:e7-e13. Available from: http://circ. ahajournals.org/content/137/1/e7

11. Greif R, Lockey AS, Conaghan P, Lippert A, DeVries W, Monsieur KG. European Resuscitation Council Guidelines for Resuscitation 2015: Section 10. Education and implementation of resuscitation. Resuscitation. [Internet]. 2015 [cited 2019 Feb 20];95:288-301. Available from: https://www.ncbi.nlm.nih.gov/ pubmed/26477418

12. Gonzalez MM, Timerman S, Oliveira RG, Polastri TF, Dallanm LAP, Araújo $S$, et al. I Guideline for Cardiopulmonary Resuscitation and Emergency Cardiovascular Care - Brazilian Society of Cardiology: Executive summary. Arq Bras Cardiol. [Internet]. 2013 [cited 2019 Feb 20];101(2):2-221. Available from: http:// www.scielo.br/pdf/abc/v100n2/en_v100n2a01.pdf

13. Chung SP, Sakamoto T, Lim SH, Ma MH, Wang $\mathrm{TL}$, Lavapie F, et al. The 2015 Resuscitation Council of Asia (RCA) guidelines on adult basic life support for lay rescuers. Resuscitation. [Internet]. 2016 [cited 2019 Feb 20];105:145-8. Available from: https://www.ncbi. nlm.nih.gov/pubmed/27283062

14. Lopes MVO, Silva VM, Araujo TL. Methods for establishing the Accuracy of Clinical Indicators in Predicting Nurseing Diagnoses. Int J Nurs Knowl.
[Internet]. 2012 [cited 2019 Nov 25];23(3):134-9. Available from: https://www.ncbi.nlm.nih.gov/ pubmed/23043652

15. Melo RP, Moreira RP, Fontenele FC, Aguiar ASC, Joventino ES, Carvalho EC. Criteria for selection of experts for validation studies of nursing phenomena. Rev Rene. [Internet]. 2011 [cited 2019 Nov 25];12(2):424-31. Available from: https://www.redalyc.org/ pdf/3240/324027975020.pdf

16. Guimarães FJ, Carvalho ALRF, Pagliuca LMF. Elaboration and validation of an assistive technology assessment questionnaire. Rev Eletr Enferm. [Internet]. 2015 [cited 2019 Feb 22];17(2):302-11. Available from: https://revistas.ufg.br/fen/article/ view/28815/19579

17. Cunha CM, Almeida OP Neto, Stackfleth R. Main psychometric evaluation methods of measuring instruments reliability. Rev Atenção Saúde [Internet]. 2016 [Cited 2019 Nov 25];14(49):98-103. Available from: http://seer.uscs.edu.br/index.php/revista_ ciencias_saude/article/view/3671/pdf

18. Polit DE, Beck CT, Owen SV. Is the CVI an acceptable indicator of content validity? Appraisal and recommendations. Res Nurs Health. [Internet]. 2007 [Cited 2019 Feb 22];30(4):459-67. Available from: https://www.ncbi.nlm.nih.gov/pubmed/17654487

19. Segura Melgarejo F, Pardo Ríos M, Vera Catalán T, Juguera Rodríguez L, Pérez Alonso N, Leal Costa C, et al. Design and validation of a tool for the evaluation of the quality of Cardiopulmonary Resuscitation: SIEVCA-CPR 2.0 ${ }^{\circledR}$. Intensive Crit Care Nurs. [Internet]. 2018 [Cited 2019 Feb 20];45:72-7. Available from: https://www. ncbi.nlm.nih.gov/pubmed/29366654

20. Galindo-Neto NM, Alexandre ACS, Barros LM, Sá GGM, Carvalho KM, Caetano JA. Creation and validation of an educational video for deaf people about cardiopulmonary resuscitation. Rev. Latino-Am. Enfermagem [Internet]. 2019 [Cited 2019 Mar 20]; 27:e3130. Available from: http://www.scielo.br/pdf/ rlae/v27/0104-1169-rlae-27-e3130.pdf

21. Yannopoulos D, Aufderheide TP, Abella BS, Duval S, Frascone RJ, Goodloe JM, et al. Quality of CPR: an important effect modifier in cardiac arrest clinical outcomes and intervention effectiveness trials. Resuscitation [Internet]. 2015 [Cited 2019 Feb 20]; 94:106-13. Available from: https://www.ncbi.nlm.nih. gov/pubmed/26073276

22. Perdomo BJ, Dávila D, Flores M, Morales OA. Material educativo computarizado sobre salud bucal diseñado para sordos. Experiencia en Mérida, Venezuela. Multiciencias [Internet]. 2014 [Acceso $20 \mathrm{feb}$ 2019];14(3):289-96. Disponible en: http://www.saber. ula.ve/handle/123456789/39746 
23. Ahmadi M, Abbasi M, Bahaadinbeigy K. Design and implementation of a software for teaching health related topics to deaf students: the first experience in Iran. Acta Inform Med [Internet]. 2015 [Cited 2019 Feb 20]; 23(2):76-80. Available from: https://www.ncbi.nlm.nih. gov/pmc/articles/PMC4430007/

24. Len B, Sherry S. Reflections on deaf education: perspectives of deaf senior citizens. Educ Gerontol. [Internet]. 2015 [Cited 2019 Feb 20];41(3):226-37. Available from: https://www.tandfonline.com/doi/abs/1 $0.1080 / 03601277.2014 .951194$

25. Sanderson SC, Suckiel SA, Zweig M, Bottinger EP, Jabs EW, Richardson LD. Development and preliminary evaluation of an online educational video about wholegenome sequencing for research participants, patients, and the general public. Genet Med. [Internet]. 2016 [Cited 2019 Feb 20];18(5):501-12. Available from: https://www.ncbi.nlm.nih.gov/pubmed/26334178

26. Eltorai $A E$, Sharma $P$, Wang J, Daniels AH. Most American Academy of Orthopaedic surgeons' online patient education material exceeds average patient reading level. Clin Orthop Relat Res. [Internet]. 2015 [Cited 2019 Feb 20];473(4):1181-6. Available from: https://www.ncbi.nlm.nih.gov/pubmed/25475715 27. Heim N, Faron A, Fuchs J, Martini M, Reich RH, Löffler $\mathrm{K}$. Comprehensibility of online-based patient education material in ophthalmology. Ophthalmologe. [Internet]. 2017 [Cited 2019 Feb 20];114(5):450-6. Available from: https://www.ncbi.nlm.nih.gov/pubmed/27613545

28. Soares JE, Soares NL, Freitas BH, Bortolini J. Validation of an instrument for the evaluation of adolescents' knowledge about Hansen's disease. Acta Paul Enferm. [Internet]. 2018 [Cited 2019 Feb 20]; 31(5):480-8. Available from: http://www.scielo.br/pdf/ ape/v31n5/en_1982-0194-ape-31-05-0480.pdf

29. Medina N, Fernández G, Cruz T, Jordán N, Trenche M. Community participation in the development and validation of a school violence observation instrument. Prog Community Health Partnersh [Internet]. 2016 [Cited 2019 Feb 20];10(2):251-8. Available from: https:// www.ncbi.nlm.nih.gov/pmc/articles/PMC4926646/

30. Hernández C, Pulido JL, Arias JE. Information technology in learning sign language. Rev. Salud Pública [Internet].
2015 [Cited 2019 Feb 20];17(1):61-73. Available from: http://www.redalyc.org/html/422/42242322006/ Creative Commons (CC BY).

This license lets others distribute, remix, tweak, and build upon original creation. This is the most accommodating of licenses offered. Recommended for maximum dissemination and use of 